\title{
Interfacial Quality Prediction Model for Al/Steel Sheets During Friction Stir Assisted Double-Sided Incremental Forming with Synchronous Bonding
}

\author{
Renhao Wu \\ Shanghai Jiao Tong University \\ Meng Li \\ Shanghai Jiao Tong University \\ Xinmei Liu \\ Shanghai Jiao Tong University \\ Zhiyun Yang \\ Shanghai Jiao Tong University \\ Jun Chen ( $\nabla$ jun_chen@sjtu.edu.cn ) \\ Shanghai Jiao Tong University
}

\section{Research Article}

Keywords: Dissimilar Al/steel bonding, friction stir, double-sided incremental forming, process quality prediction, interfacial performance.

Posted Date: May 24th, 2021

DOI: https://doi.org/10.21203/rs.3.rs-531361/v1

License: (c) (i) This work is licensed under a Creative Commons Attribution 4.0 International License. Read Full License

Version of Record: A version of this preprint was published at The International Journal of Advanced Manufacturing Technology on November 8th, 2021. See the published version at https://doi.org/10.1007/s00170-021-08168-y. 


\title{
Interfacial quality prediction model for $\mathrm{Al} / \mathrm{steel}$ sheets during friction stir assisted double-sided incremental forming with synchronous bonding
}

Renhao Wua ${ }^{\mathbf{a}, \mathbf{b}}$, Meng Li ${ }^{\mathbf{a}, \mathbf{b}}$, Xinmei Liua ${ }^{\mathbf{a}, \mathbf{b}}$, Zhiyun Yang ${ }^{\mathbf{a}, \mathbf{b}}$, Jun Chen ${ }^{\mathbf{a}, \mathbf{b}^{*}}$

a Department of Plasticity Technology, School of Materials Science and Engineering, Shanghai Jiao Tong University, Shanghai 200030, China

b National Engineering Research Center of Die \& Mold CAD, School of Materials Science and Engineering, Shanghai Jiao Tong University, Shanghai 200030, China

\begin{abstract}
The widely investigated $\mathrm{Al} /$ steel laminated structures are challenged with subsequent plastic deformation due to the existence of interfacial brittle intermetallic compound layer. To overcome this drawback, a newly proposed thermomechanical forming technology as friction stir assisted double-sided incremental plastic forming with synchronous solid-state interfacial bonding is utilized to fabricate laminated structures, which can meet requirement of plastic deformation of laminates. Typical interfacial bonding performances produced by a series of experiments classified as sound bonding, de-bonding, over-thinning, penetration and crack are assessed. Local working peak temperature and maximum forming force in loading area are recorded and evaluated during stable bonding-forming stage. Considering heat-force coupling effect, a pressure-strain-temperature based prediction model is modified to assess process quality, which is conformed to experimental results. This work can help obtain proper process window to fabricate $\mathrm{Al} /$ steel laminated parts and shall also inspire to build guidance of related thermomechanical joining-with-forming processes to achieve high interfacial performance.
\end{abstract}

Key words: Dissimilar Al/steel bonding; friction stir; double-sided incremental forming; process quality prediction; interfacial performance.

\footnotetext{
* Corresponding author: J. Chen

Tel: +86-21-62813432; Email: jun_chen@sjtu.edu.cn

\section{Introduction}


The demands of lightweight laminated structures are emerging in shipping, maritime, and kitchenware industries because of their comprehensive performance in high relative strength, vibration absorption and corrosion resistance. In practical applications, steel to aluminum alloy laminate is receiving more attentions attributed to its wide applicability and cost-effectiveness. Traditionally, the aluminum alloy is bonded with steel by a few mechanical approaches, like self-piercing riveting and clinching processes[1,2]. Nevertheless, these mechanical methods [3] are often limited by the thickness of metallic sheet and the ductility. In recent years, some welding solutions, including current or friction resistance spot joining, cold metal transfer welding, and friction stir welding (FSW) [4-6] were investigated to join the two dissimilar materials by importing heat input. Among these methods, FSW originally devised as a solid-state bonding process exhibits flexible applicability for joining dissimilar metals.

Boccarusso et al. [7] made force analysis and microstructure evolution on the friction stir lap welding process of dissimilar AA6082/MgAZ31 sheets, through which the dissimilar joint was successfully obtained with fine metallurgical bonding free of micro crack and penetration. Chung et al. [8] investigated the interfacial performance of the joint of dissimilar steels F82H/SUS304, which indicated that the sheets are just simply mixed without diffusion. More derived processes were also developed based on FSW. Sapanathan et al. [9] recently developed a friction melt bonding process, by which DP980 and AA6061-T6 layers were bonded and Fe-Al intermetallic compound (IMC) layer formed. Friction stir dovetailing (FSD) is another newly developed process to join dissimilar materials [10], which can simultaneously produce interfacial metallurgical bonding mixed with mechanical occlusion. A simulation approach was also proposed to project bonding performance of aluminum alloy/steel laminates with thick section by FSD [11]. Shen et al. [12] reported the materials intermixing, sever flow area behaviors and micro induced cracking mechanism in refill friction stir spot welding approach for heterogeneous aluminum alloy sheets. Chen et al. [13] conducted FSW experiments to study the effects of forming tools with $\mathrm{V}, \mathrm{K}$ and $\mathrm{X}$ groove types in two types of S355JR/316 steels dissimilar welding.

One of the most attractive laminated structures consists of aluminum alloy and steel which are conventionally produced by friction stir related processes [14]. Nevertheless, specific interfacial IMCs with typical components and morphology may cause deteriorated 
physicochemical properties due to the existence of Al-rich phase, interfacial voids and hook effect $[15,16]$, which may limit further plastic deformation of Al-steel laminates. More effective dissimilar bonding methods were developed to obtain large deformation of whole part under special requirements. Huang and Yanagimoto [17] proposed a thermally assisted joining technology via local plastic deformation that combines mechanical anchoring and fast diffusion bonding features to achieve high production performance, which is an alternative solution for joining or assembling Al/steel laminated parts. Recently, Li et al. [18] developed a process window for a novel friction stir assisted thermomechanical forming process to fabricate $\mathrm{Al} / \mathrm{steel}$ solid-state bonded parts with synchronous incremental plastic deformation.

Govindaraj et al. [19] studied the bond strength of cold roll bonded aluminum sheets and established a applied fit model to the experimental outcomes. Donati and Tomesani [20] proposed analytical methods for evaluating the quality of seam welding in aluminum alloy extruded profiles. However, bonding quality prediction still needs further investigations for the new dissimilar bonding processes. Therefore, a prediction criterion model for assessing bonding states is particularly worth exploring to help confirm interfacial process quality for some new technologies combining bonding and plastic deformation.

In this work, friction stir assisted experimental campaigns of double-sided incremental forming (DSIF) with synchronous pin-less solid-state bonding of DC05 and AA5052 sheets are carried out. The interfacial bonding and through thickness deformation performances of the formed parts are evaluated by analyzing the thermomechanical effects of peak temperature and axial loading force. Moreover, a pressure-strain-temperature based interfacial bonding prediction model is modified and validated, which can be successfully used to assess process quality.

\section{Experimental campaign}

\subsection{Materials and experimental procedures}

To achieve the proposed friction stir assisted DSIF with synchronous bonding (FS-DSIF\&SB) concept, prepared dissimilar sheets are processing in a DSIF platform as illustrated in Fig. 1a. Two horizontal forming tools driven by servo motors connected to CNC system. The forming process mainly contains setting and processing stages: 


\section{Step I: setting stage}

$1.0 \mathrm{~mm}$ thick AA5052-H32 as outer sheet and $0.8 \mathrm{~mm}$ thick deep-drawing steel DC05 as inner sheet are cut in $180 \mathrm{~mm} \times 180 \mathrm{~mm}$. The physical and chemical materials properties of as-received AA5052 and DC05 sheets are included in Tables 1 - 2. The contact surfaces of the two dissimilar sheets are carefully polished by electric brush to remove the oxide films. Then all surfaces are rinsed with alcohol to remove debris and oil stains. The outer side as AA5052-H32 sheet is evenly sprayed with high temperature resistant black paint and graphite-based lubricant for temperature infrared sensor temperature detection and ST - AA5052 contact friction reduction. Infrared camera (ThermoIMAGER 160) is used to capture the layer temperature history through the process, especially the working peak temperature in localized loading zone.

Table 1 Nominal chemical composition of as-received materials sheets (in wt\%).

\begin{tabular}{ccccccccccc}
\hline Materials & $\mathrm{C}$ & $\mathrm{P}$ & $\mathrm{S}$ & $\mathrm{Mg}$ & $\mathrm{Si}$ & $\mathrm{Fe}$ & $\mathrm{Mn}$ & $\mathrm{Cr}$ & Others & $\mathrm{Al}$ \\
\hline AA5052 & -- & -- & -- & $2.2-2.8$ & 0.25 & 0.4 & 0.1 & $0.15-0.35$ & 0.35 & Bal. \\
DC05 & 0.06 & 0.02 & 0.02 & -- & 0.02 & Bal. & 0.35 & -- & -- & 0.01 \\
\hline
\end{tabular}

Table 2 Mechanical properties of as-received materials.

\begin{tabular}{cccccc}
\hline Materials & $\begin{array}{c}\text { Density } \\
\left(\mathrm{g} / \mathrm{cm}^{3}\right)\end{array}$ & $\begin{array}{c}\text { Young's } \\
\text { modulus }(\mathrm{GPa})\end{array}$ & $\begin{array}{c}\text { Yield strength } \\
(\mathrm{MPa})\end{array}$ & $\begin{array}{c}\text { Melting temperature } \\
\left({ }^{\circ} \mathrm{C}\right)\end{array}$ & $\begin{array}{c}\text { Elongation at break } \\
(\%)\end{array}$ \\
\hline AA5052 & 2.7 & 69 & 175 & 607 & 15 \\
DC05 & 7.85 & 200 & 136 & 1500 & 33.9 \\
\hline
\end{tabular}

After calibrating initial loading position of tools, pretreated base sheets are firmly camped by fixtures with the same rolling sequence in working space. Corresponding NC toolpath codes are built into CNC system to achieve designed shape of part.

Step II: processing stage

As displayed in Fig. 1b, the rotational pin-less master tool (MT) feeds at a fixed rate as 720 $\mathrm{mm} / \mathrm{min}$ for process stability. The slave tool (ST) moves coordinately to provide sufficient back support for MT. As shown in Fig. 1c, the high-speed rotational rod-shaped rigid MT generates adequate friction stir induced heat on the contact area conducted to sheets and tools to complete the dissimilar thermomechanical bonding. Thus, effect of material flow can be mainly reflected by different rotation speed of MT. Meanwhile, the plastic deformation of localized loading material is realized with incremental step down by pre-designed spiral toolpath, as 
shown in Fig. 1d. Ruled by the coupling effects of friction induced heat and loading force, interfacial solid-state bonding is achieved at localized loading area with incremental plastic deformation.

In this step, the process parameters can be adjusted according to specific materials and forming conditions to control frictional heat input. Additionally, different forming performance modes may appear due to the complex thermomechanical effects through the process. Notably, undesirable cutting chips may be produced when the rotational MT firmly contacts with the DC05 sheet. These chips shall be removed with heat air gun in time to protect surface quality of the part.
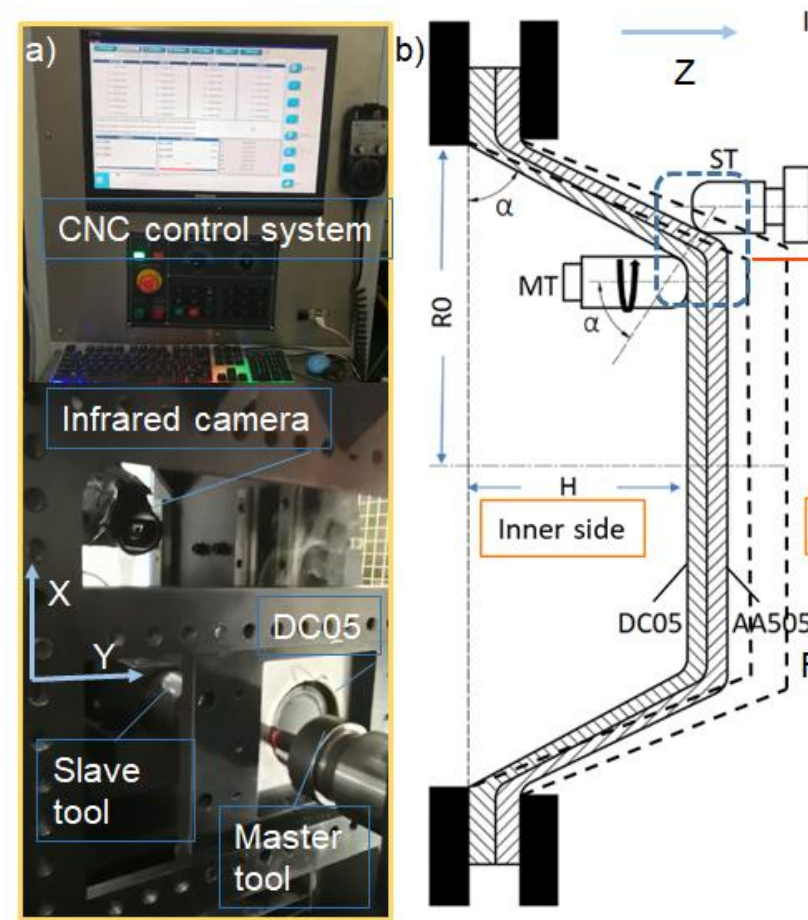

Moving direction 
reach a relatively stable range after initial rapid rise, maximum temperature of localized loading area can reach about $420{ }^{\circ} \mathrm{C}$ at forming height $5 \mathrm{~mm}(\sim 30 \%$ of total forming time). The maximum working temperature is the peak value of the whole part in real time. At the initial forming stage, Z-axial force history of MT is in a similar trend with working temperature, which is consistent with the features of FSW related processes. However, the maximum MT Z-axial force is only about $1 \mathrm{kN}$ and MT Z-axial force at stable forming stage basically lowers than $800 \mathrm{~N}$. It is quite smaller than that in $\mathrm{Al} /$ steel FSW process.

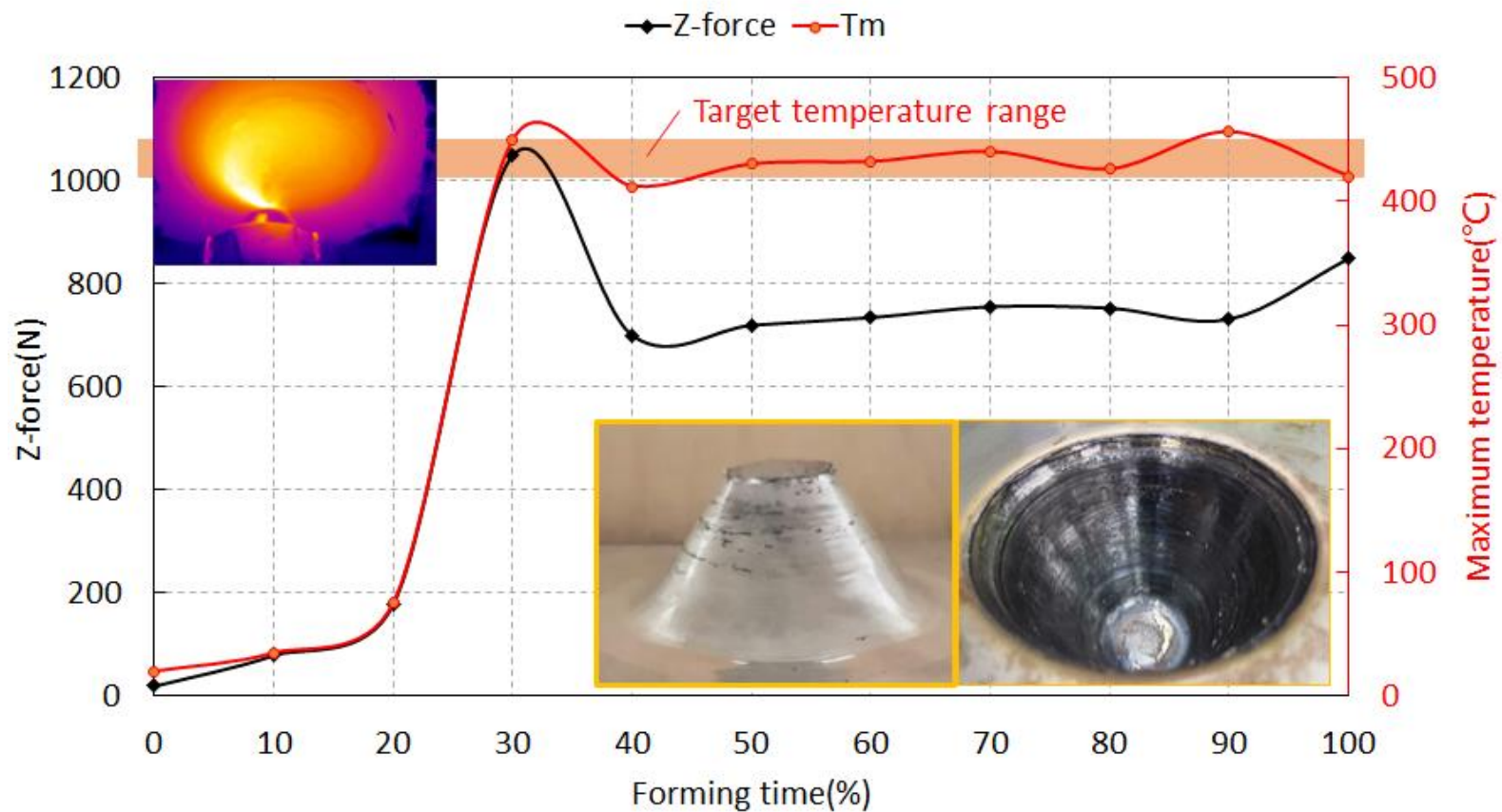

Fig. 2 History of MT Z-force and maximum temperature during process.

The most important concern of the process is the interfacial bonding states of laminated parts. Typical forming appearance modes are illustrated in Fig. 3, which can be distinguished as follows: successfully bonded (e.g., S0.25- $\alpha 47.5-R 3200)$, de-bonded (e.g., S0.25- $\alpha 45-R 3200$ ), penetration (e.g., S0.25- $\alpha 62.5-R 3200$ ), excessive thinning (e.g., $S 0.15-\alpha 60-R 3600$ ) and crack (e.g., S0.35- $\alpha 60-R 3600)$. The displayed pictures at the bottom row are the macro peeling test results to demonstrate rationality of typical classification. The reasons of different interfacial bonding states shall be attributed to the main factors during the process: strain, pressure, temperature and materials properties. In the following section, the process quality assessment and prediction method for obtaining desirable forming appearance mode as Fig. $3 a$ is introduced by evaluating above individual and interactive factors. 


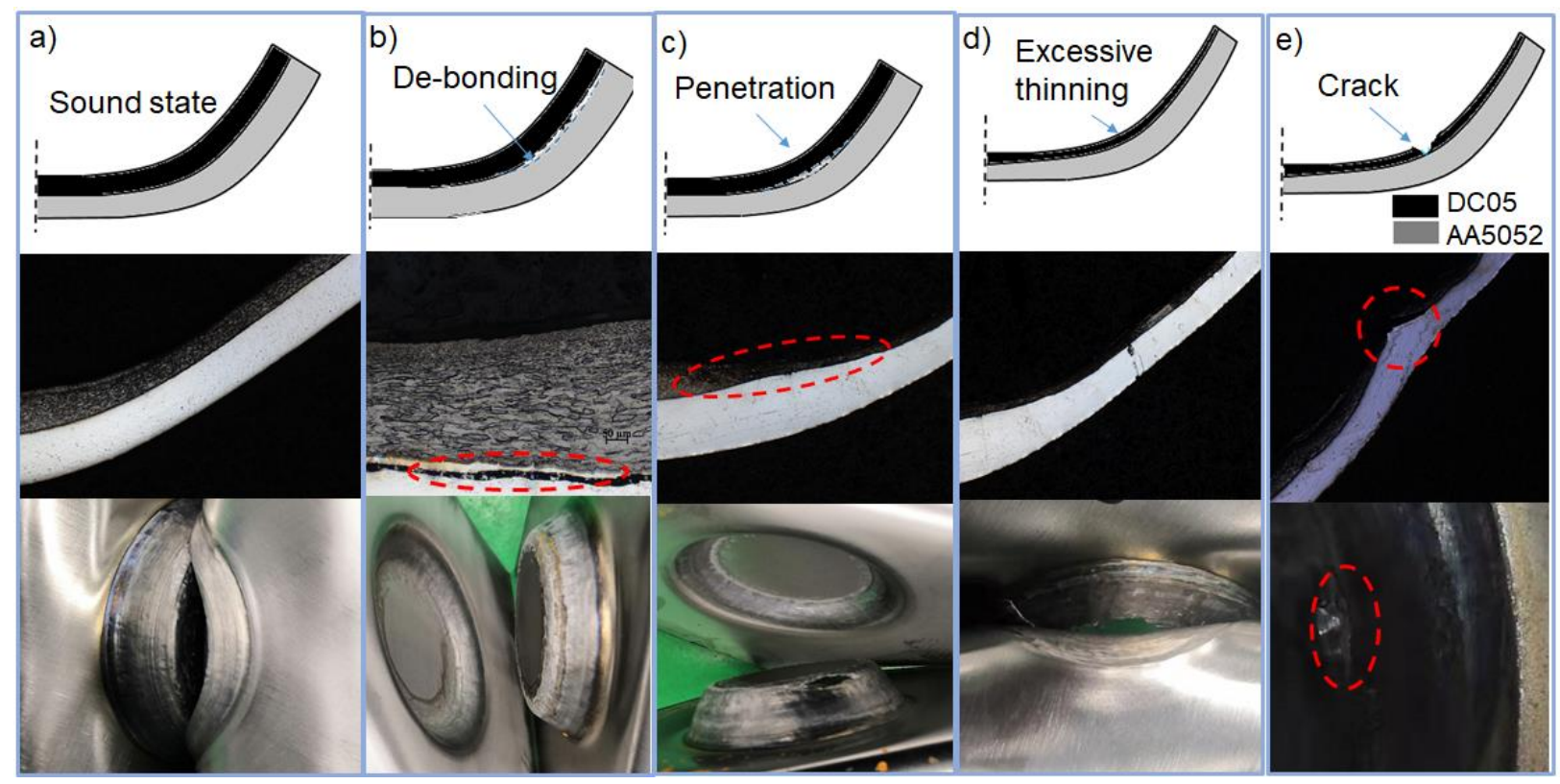

Fig. 3 Illustration and actual process appearance and interfacial peeling behavior of 5 typical types of forming modes.

\section{Analytical model for predicting interfacial process quality}

\subsection{Dissimilar sheets deformation in current loading area}

The magnitude and distribution of loading forces conducted by rigid forming tools are the main driving sources for materials plastic deformation and interfacial bonding. Thus, it is significant to take an insight of cyclic and localized loading of rigid forming tools in laminated parts to understand the materials response.

Study of deformation mechanism in DSIF process [21] reveals that ST mainly provides back pressure support for AA5052 layer. Therefore, at the compressive zone, the back support of ST and effects of stretching-bending $[22,23]$ are dominated along the through-thickness direction. The shearing stress $\tau_{\theta t}$ is resolved through the frictional force induced by rigid MT. Taking a small element into account in through thickness direction of sheet at the contact area as displayed in Fig. 4, the normal stress components $\sigma_{t}, \sigma_{\theta}$, and $\sigma_{\varphi}$ are main driven sources of the element along the thickness, tangential and circumferential directions, respectively. Details on the deformation mechanisms can be referred to our previous work [24]. 


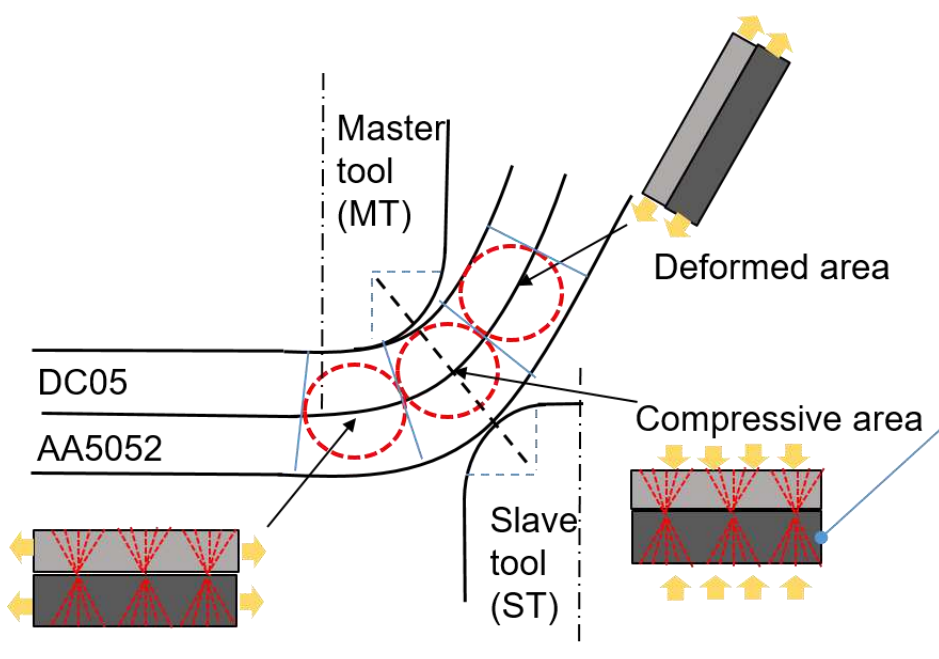

Tensile area

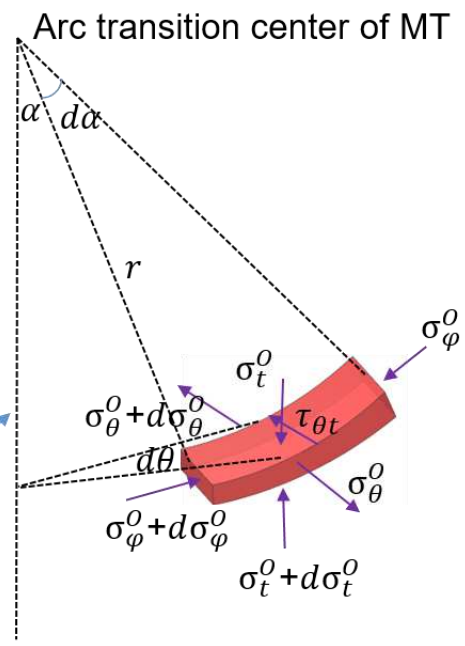

Stress state of element

Fig. 4 Illustration of deformation mode of sheets in FS-DSIF\&SB process.

As materials undergo incremental plastic deformation and fast interfacial diffusion, the complex material behaviors are macroscopically characterized as sheet thinning and bonding. The thickness variation of laminated sheet is an important indicator of load bearing. During conventional incremental sheet forming process, wall thickness distribution is usually regarded to follow cosine law which may be also extended to the laminated sheet. However, it is not suitable for DSIF process due to the requirement of adequate contact squeeze by ST. In order to control thickness distribution of dissimilar sheets to prevent losing contact between ST and outer sheet AA5052, total thickness of two metallic sheets can be estimated by Eq. (1), which is modified according to a previous thickness distribution prediction model [25].

$t_{g}=t^{I}+t^{o}=t_{0}\left(1-\left[\left(1+a h^{2}+b h\right)(1-\cos \alpha)\right]\right)$

Where $t_{g}$ is the final total thickness of the laminated sheet and $t_{0}$ is the original total thickness of the two sheets. $a$ and $b$ are the fitting parameters and $h$ is the current forming height. Superscripts $I$ and $O$ represent the inner (DC05) and outer (AA5052) sheets, respectively. During this thermomechanical process, thinning amounts on inner and outer layers are assumed as even and equally proportional.

The actual fabricated $\mathrm{Al} /$ steel laminated part with thickness distribution of test $S 0.25-\alpha 55-R 3200$ with designed forming height $20 \mathrm{~mm}$ is displayed as Fig. 5 , which also confirms the evenly thinning deformation mode. 


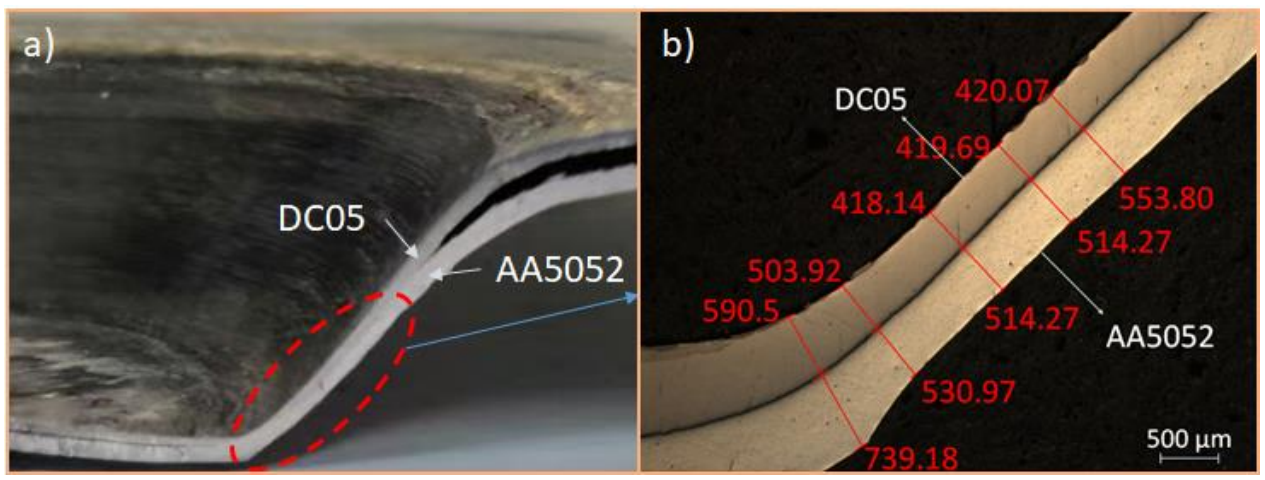

Fig. 5 Fabricated Al/steel laminated part with thickness distribution. (a) successfully fabricated part, (b) wall thickness distribution.

Localized loading area of conical parts in ISF-related process is commonly recognized as plane strain condition, i.e. $\varepsilon_{\theta}=0$ [26]. Based on the assumption of plastic volume conservation, $\varepsilon_{\theta}+\varepsilon_{t}+\varepsilon_{\varphi}=0$. Then, the total equivalent plastic strain for a localized loading area can be calculated via the strain component $\varepsilon_{t}$,

$\bar{\varepsilon}_{p}=\sqrt{\frac{2}{3} \varepsilon_{i j} \varepsilon_{i j}}=\sqrt{\frac{2}{3}\left(\varepsilon_{t}^{2}+\varepsilon_{\varphi}^{2}\right)}=-\frac{2}{\sqrt{3}} \varepsilon_{t}=-\frac{2}{\sqrt{3}} \operatorname{In} \frac{t_{g}}{t_{0}}$

\subsection{Working temperature prediction}

In addition to mechanical deformation, the working temperature of loading area as an important detection indicator can be approximately treated as the peak temperature during the thermomechanical incremental forming process. Referring to previous study in friction stir related processes [26], the peak temperature model can be written in a form of $\frac{T_{\text {peak }}}{T_{\text {melting }}}=\kappa\left(\frac{R^{2}}{v \cdot 10^{4}}\right)^{\beta}$. Where $T_{\text {melting }}$ is the melting temperature of AA5052, and fitting parameters $\beta, \kappa$ vary between $0.04 \sim 0.06,0.65 \sim 0.75$ [27], respectively. To properly describe the heat response in FS-DSIF\&SB process, our previous simulation work [28] has revealed that increased ratio of step down and forming angle (i.e. $S / \alpha$ ) has a positive effect on the peak temperature of loading area in the set parameters range. According to the similar thermomechanical condition, the peak temperature model in FSW-related process can be modified as Eq. (3) to establish relationship for base material and process parameters including step down $S$, forming angle $\alpha$, feed rate $v$ and rotation speed $R$ in the proposed 


\section{FS-DSIF\&SB process.}

$$
\frac{T_{\text {peak }}}{T_{\text {melting }}}=\kappa\left(\frac{R^{2}}{v \cdot 10^{4}}\right)^{\beta}\left(\frac{S}{\alpha}\right)^{\gamma}
$$

Where $\beta, \kappa, \gamma$ are fitting parameters for the model. Due to the pin-less tool configuration, lower values of parameters are taken to suppress the influence of process parameters. By coding in MATLAB, $\beta=\gamma=0.04$ and $\kappa=0.75$ are suitable to fit measured experimental results.

To evaluate interfacial bonding states, a series of experiments with different parameters combinations are carried out to fabricate laminated conical parts as listed in Table 3.

Table 3 Process parameters for forming Al/steel sheets.

\begin{tabular}{cccc}
\hline Test No. & Step down $S(\mathrm{~mm})$ & Wall angle $\alpha\left(^{\circ}\right)$ & Rotational speed $R(\mathrm{RPM})$ \\
\hline (1) & 0.25 & 55 & 2600 \\
(2) & 0.35 & 60 & 3600 \\
(3) & 0.10 & 55 & 3200 \\
(4) & 0.25 & 62.5 & 3200 \\
(5) & 0.25 & 55 & 3200 \\
(6) & 0.25 & 45 & 3200 \\
(7) & 0.40 & 55 & 3200 \\
(8) & 0.35 & 50 & 2800 \\
(9) & 0.15 & 60 & 3600 \\
(10 & 0.25 & 67.5 & 2000 \\
(11) & 0.35 & 47.5 & 2800 \\
(12) & 0.15 & 50 & 2800 \\
(13) & 0.35 & 60 & 3600 \\
(14) & 0.15 & 55 & 2800 \\
(15) & 0.25 & 50 & 3800 \\
(16) & 0.15 & 50 & 2000 \\
(17) & 0.15 & 50 & 3600 \\
(18) & 0.15 & 47.5 & 2800 \\
(19) & 0.25 & 45 & 3200 \\
(20) & 0.15 & & 1500 \\
\hline
\end{tabular}

The predicted peak temperature of the loading area can provide an intuitive estimation on interfacial bonding thermal field as a result of heat generation. It also works as an internal variable affecting flow stress, which will be substituted into the calculation process of modified ' $Q$ ' criterion as bonding quality assessment and prediction method. The prediction error between the predicted peak temperature and measured result is defined as, 
$E r r=a b s\left(\frac{T_{E s}-T_{M e}}{T_{M e}}\right) \times 100 \%$

As shown in Fig. 6, the error marked on each column between measurement and prediction is rather acceptable (the largest relative error is $10.15 \%$, the smallest relative error is $0.32 \%$ and the mean relative error is $3.05 \%$ ), which proves that the peak temperature model is proper for FS-DSIF\&SB process. Although temperature distribution is different between inner and outer sheets due to their difference in specific heat capacity and thermal resistance in interfacial heat conduction. However, as for a specific metallic thin sheet (AA5052 or DC05, less than $1.0 \mathrm{~mm}$ thick), the difference on temperature distribution through the sheet thickness can be ignored. Therefore, the temperature of AA5052 side at the dissimilar interface is approximately equal to that on AA5052-ST side measured by the infrared thermometer. Among the measured consequents as shown in Fig. 4, the working temperature of each test is much lower than melting point of AA5052 sheet $\left(\sim 600{ }^{\circ} \mathrm{C}\right)$. Therefore, dissimilar AA5052/DC05 sheets are in solid-state bonding during the process.

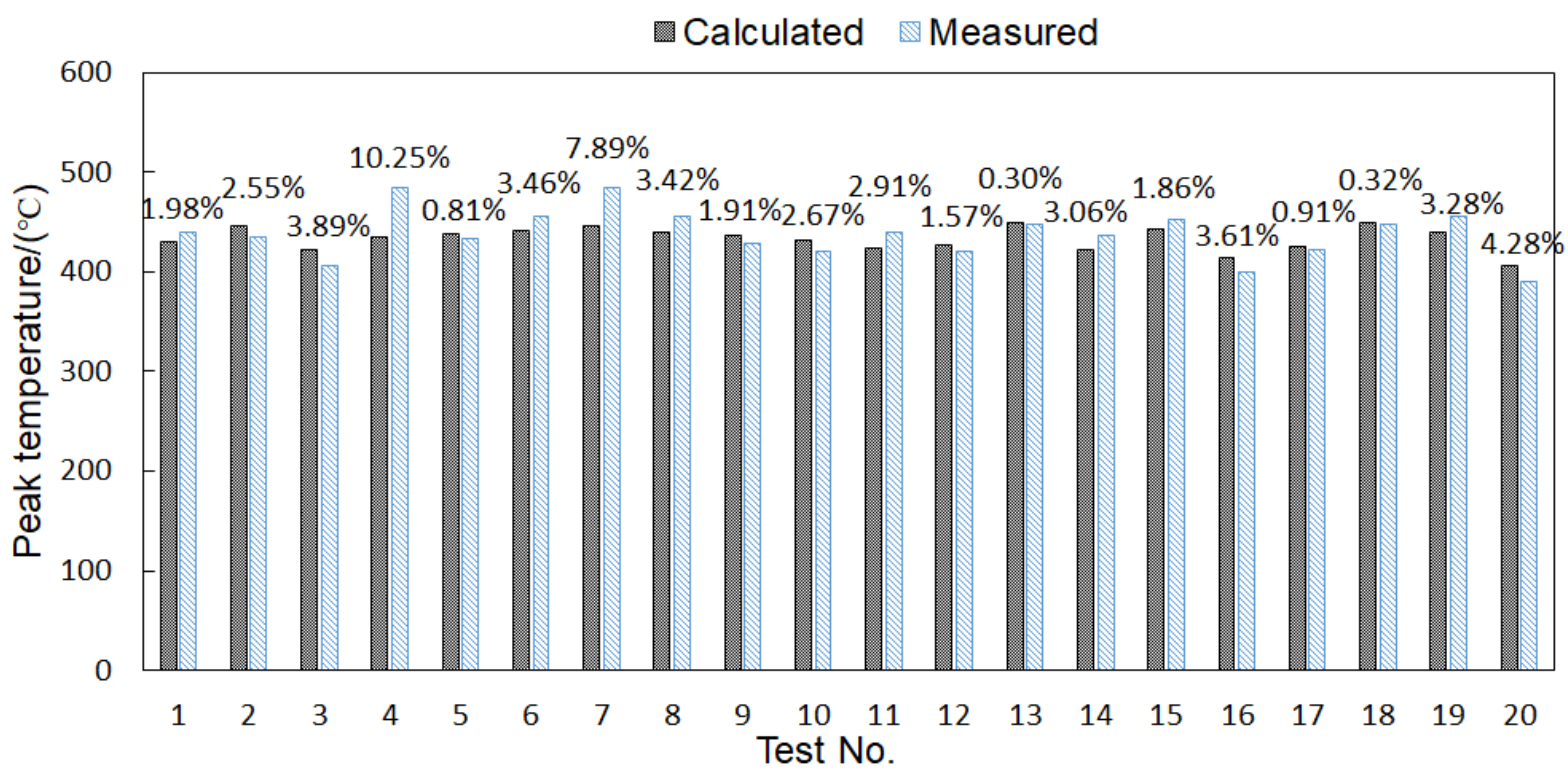

Fig. 6 Comparison of calculated and measured peak temperature between prediction and experiment in FS-DSIF\&SB tests.

\subsection{Criterion for predicting bonding quality under thermomechanical effect}

Referring to previous study on predicting seam welding quality [20], the ratio of interfacial pressure to equivalent stress of base material is an important factor to judge bonding condition. 
This pressure-time-flow principle is in an integrated form as follows,

$K=\int_{L} \frac{P}{\bar{\sigma}_{S}} d l \geq K c$

Where $K c$ is the critical value and $l$ is the welding length. However, as stated on other solid-state bonding research [3], the induced plastic strain via the whole process is also reported that highly contributes to atoms interaction and interfacial anchor morphology, which proves the significance of plastic strain on mechanical and metallurgic bonding mechanisms. Moreover, thermal effect shall be considered in a bonding process. Here, a $Q$ criterion is derived as an independent dimensionless target to predict current bonding state. By integrating the plastic strain with the ratio of interfacial normal pressure to equivalent stress of the soft outer base material.

$Q=\int_{0}^{\bar{\varepsilon}_{p}} \frac{P}{\bar{\sigma}_{S}^{O}} d \bar{\varepsilon}_{p}$

Corresponding to the interfacial materials bonding response in elevated temperature condition, interfacial pressure $P$ and yield stress $\bar{\sigma}_{S}^{O}$ of AA5052 are treated as dependent on current working temperature [24].

$\bar{\sigma}_{S}^{O}=178 \times\left[1-\left(\frac{T-25}{607}\right)^{0.9}\right]$

The interfacial pressure $P$ and equivalent strain illustrated in Fig. 4 can also be calculated by the combination of forming parameters as stated in our previous work [24]. Therefore, by submitting specific forming parameters into Eq. (6) under simplified proportional loading condition, the bonding quality prediction criterion can be written as,

$Q=\left(\frac{\left(2 \sqrt{3}+\mu \frac{\sigma_{t b}^{O}}{\bar{\sigma}_{S}^{O}}\right)\left(R_{t}+t^{I}\right)^{0.5 \mu}}{\mu\left(R_{t}+t_{g}\right)^{0.5 \mu}}-\frac{2 \sqrt{3}}{\mu}\right) \frac{2}{\sqrt{3}} \operatorname{In}\left(\frac{1-\left[\left(1+a h^{2}+b h\right)(1-\cos \alpha)\right]}{t_{0}}\right)$

A criterion model is thus modified to predict the interfacial bonding states as checking the input process parameters before conducting the FS-DSIF\&SB technology. A critical value $Q c$ which can reflect the bonding quality shall be set. Only when the calculated $Q$ exceeds the critical threshold value the bonding quality of the fabricated part is acceptable. Hence, the 
critical determination criterion of solid-state bonding can be obtained as $Q \geq Q c$.

\subsection{Application and validation of ' $Q$ ' bonding quality prediction model}

To express the types of appearance modes as displayed in Fig. 3, thermomechanical effects of process parameters are required further investigated based on the ' $Q$ ' related bonding quality criterion. The aim of process quality prediction can be achieved then by submitting the parameters combination into the ' $Q$ ' criterion. Here, the bonding state of each test is analytically evaluated according to the experimental setup in Table 3 to directly reveal the influences of forming parameters and induced heat-force conditions. The $Q$ value of each test is obtained from Eq. (7) and then plotted in Fig. 7 (solid dots and squares).

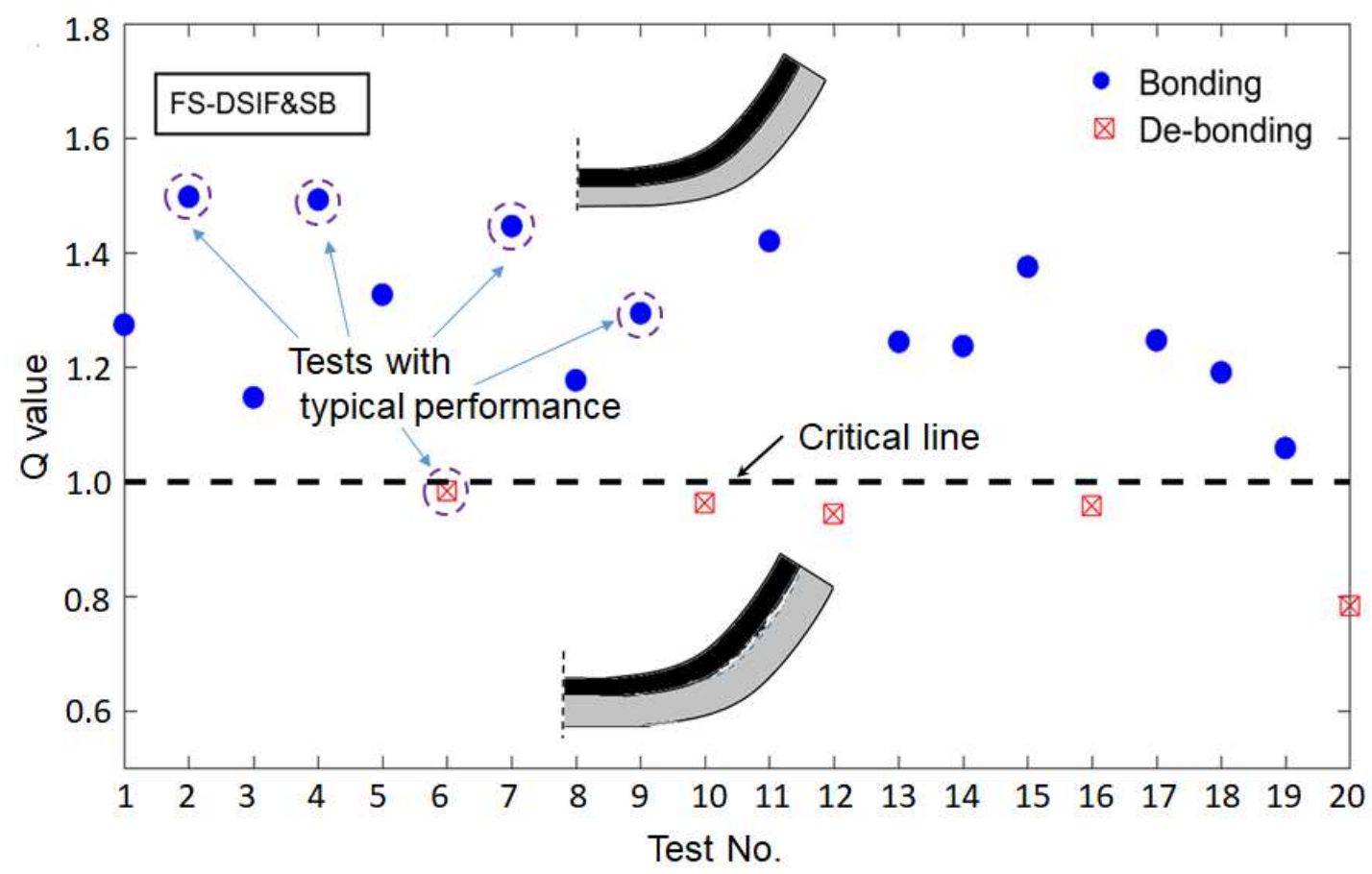

Fig. 7 Prediction model for assessing interfacial bonding states by evaluating $Q$ value.

Compared with the experimental results, a critical line as ' $Q=1.0$ ' in Fig. 7 clearly divides the tests into two categories: bonded and de-bonded. Hence, $Q c$ could be set as '1.0'. Moreover, if $Q$ value exceeds 1.4, damage accumulation may deteriorate into failure in service. Therefore, the calculated $Q$ value could help determine the deformed modes:

1). If $Q<1.0$, the dissimilar sheets are not successfully bonded, as shown in Fig. 3b and Fig. 8a.

2). If $1.0<Q<1.4$, the dissimilar sheets could be successfully bonded, as shown in Fig. 3a and Fig. 8b. 
3). If $Q>1.4$, the dissimilar sheets might be damaged, as shown in Figs. 3c-3e and Figs. 8c-8d.
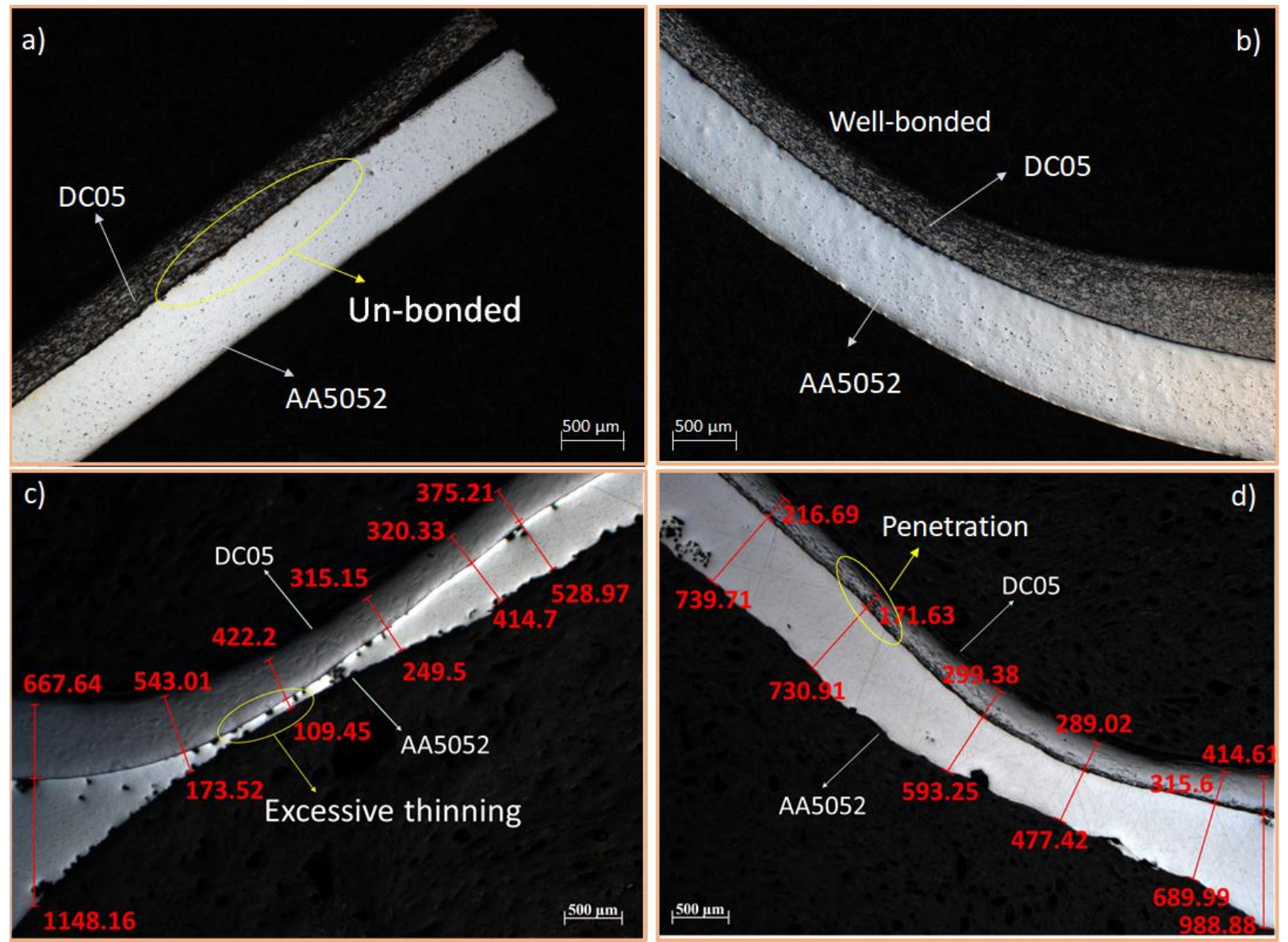

Fig. 8 Performance of fabricated parts with different forming parameters. (a) un-bonded, (b) well-bonded, (c) excessive thinning, (d) penetration.

The effects of process parameters on the dimensionless factor $Q$ can be illustrated in Fig. 9. Under low-value parameters combination (e.g., $S 0.15-\alpha 45-R 2500)$ in step down $(S \leq 0.15$ $\mathrm{mm}$ ), forming angle ( $\left.\alpha \leq 45^{\circ}\right)$ and rotation speed ( $\left.R \leq 2500 \mathrm{RPM}\right), Q$ value is generally lower than '1.0', indicating that it is almost impossible to achieve reliable interfacial bonding between dissimilar interfaces. Obviously, the $Q$ value increases with the increase of the parameters, indicating that the possibility of solid-state bonding is higher. However, excessive high-value parameters combination (e.g., $S 0.35-\alpha 60-R 3500)$ in step down $(S \geq 0.35 \mathrm{~mm})$, forming angle ( $\alpha$ $\geq 55^{\circ}$ ) and rotation speed ( $R \geq 3500$ RPM) will result in relatively high $Q$ value, which may bring about the risk of cracking and excessive thinning. According to Fig. 9, forming angle is the most influential parameter due to greater plastic deformation, which makes the closer contact between the localized loading material and rigid forming tool, thereby improving the friction stir 
effect. The guidance for selecting process parameters combination is consistent with the above discussion on the experimental results.
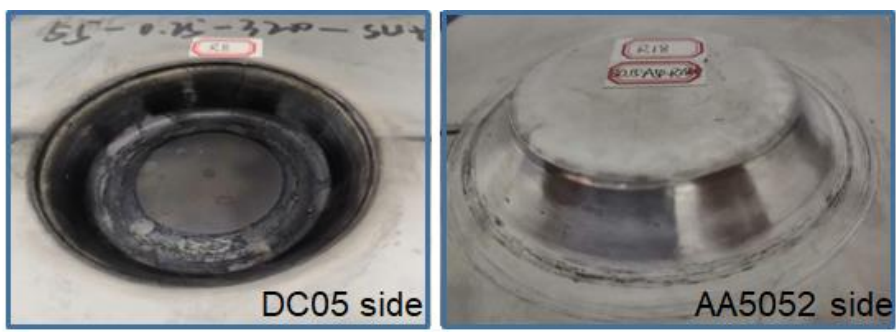

Typical fabricated part with sound bonding

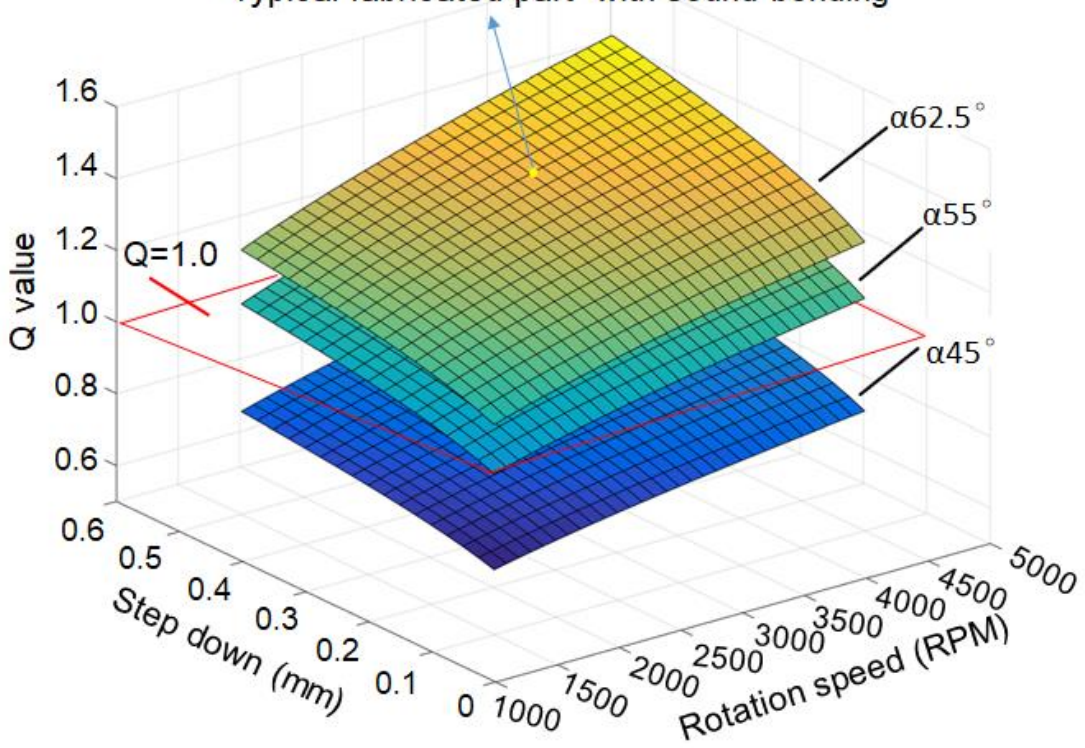

Fig. 9 Process bonding quality predicted by $Q$ response surfaces dependent on forming parameters in FS-DSIF\&SB.

\section{Conclusions}

In the present work, a newly established thermomechanical process is utilized to fabricate dissimilar laminated structures with designed shape. Bonding quality prediction method is investigated to help better understand the plastic deformation and solid-state interfacial bonding behavior. The main points are summarized as follows:

(1) Separated aluminum alloy AA5052 and steel DC05 sheets are successfully fabricated to truncated conical laminated parts by the pin-less FS-DSIF\&SB process.

(2) As a heat-force coupling process, peak temperature and forming force are in same trend. The maximum Z-axial loading force is $\sim 1 \mathrm{kN}$. The peak temperature of parts lowers than $500^{\circ} \mathrm{C}$ during the process. A modified empirical model based on forming parameters can accurately predict the peak temperature in localized loading area. 
(3) A series of 20 tests by the thermomechanical process are conducted to validate the feasibility of the forming with synchronous solid-state bonding concept. Among the tests, 5 typical types of bonding quality variation through the cross-section view are classified as sound bonding, de-bonding, over-thinning, penetration and crack.

(4) A ' $Q$ ' bonding quality prediction model is modified based on pressure-strain-temperature relationship. This criterion method provides a threshold value $Q c$ as 1.0 to determine interfacial bonding states in FS-DSIF\&SB process. This analytical method can also be extended to work for assessing other similar thermomechanical joining-with-forming processes.

(5) Based on the analytical method, a proper forming parameters window for Al/steel sheets in FS-DSIF\&SB is established within step down $S$ as $0.15 \sim 0.3 \mathrm{~mm}$, forming angle $\alpha$ as 47.5 $\sim 60^{\circ}$ and rotation speed $R$ as $2800 \sim 3200$ RPM.

\section{Acknowledgements}

The authors are grateful for the financial supports of National Natural Science Foundation of China under Grant No. 51675332 and Program of Shanghai Excellent Academic Research Leadership under Grant No. 19XD1401900.

\section{Declarations}

Ethics approval Not applicable

Consent to participate Not applicable

Consent for publication Not applicable

Conflict of interest The authors declare no competing interests

ORCID Jun Chen http://orcid. org/0000-0002-1698-3342.

\section{References}

[1] Mori K, Bay N, Fratini L, Tekkaya AE (2013) Joining by plastic deformation. CIRP Ann 62(2): 673-694. DOI: 10.1016/j.cirp.2013.05.004.

[2] Varis $J(2006)$ Ensuring the integrity in clinching process. J Mater Process Technol 174(1-3): 277-285. DOI: 10.1016/j.jmatprotec.2006.02.001.

[3] Groche P, Wohletz S, Brenneis M (2014) Joining by forming-A review on joint mechanisms, applications and future trends. J Mater Process Technol 214: 1972-1994. DOI: 10.1016/j.jmatprotec.2013.12.022.

[4] Ling Z, Li Y, Luo Z, Feng Y, Wang Z (2016) Resistance element welding of 6061 aluminum 
alloy to uncoated 22mnmob boron steel. Mater Manuf Process 31(10): 2174-2180. DOI: 10.1080/10426914.2016.1151044.

[5] Babu S, Panigrahi SK, Janaki GD (2019) Cold metal transfer welding of aluminium alloy AA2219 to austenitic stainless steel AISI 321. J Mater Process Technol 266: 155-164. DOI: 10.1016/j.jmatprotec.2018.10.034.

[6] Edwards SP, Den AJ, Zhou J, Katgerman L (2009) Physical simulation of longitudinal weld seam formation during extrusion to produce hollow aluminum profiles. Mater Manuf Process 24(4): 409-421. DOI: 10.1080/10426910802714290.

[7] Boccarusso L, Astarita A, Carlone P (2019) Dissimilar friction stir lap welding of AA 6082 Mg AZ31: Force analysis and microstructure evolution. J Manuf Process 44: 376-388. DOI: 10.1016/j.jmapro.2019.06.022.

[8] Chung YD, Fujii H, Sun Y, Tanigawa $\mathrm{H}$ (2011) Interface microstructure evolution of dissimilar friction stir butt welded F82H steel and SUS304. Mater Sci Eng A 528(18): 5812-5821. DOI: 10.1016/j.msea.2011.04.023.

[9] Sapanathan T, Jimenez-Mena N, Sabirov I (2019) A new physical simulation tool to predict the interface of dissimilar aluminum to steel welds performed by friction melt bonding. $J$ Mater Sci Technol 35(09): 2048-2057. DOI: 10.1016/j.jmst.2019.05.004.

[10] Reza-E-Rabby M, Ross K, Overman NR (2018) Joining thick section aluminum to steel with suppressed FeAl intermetallic formation via friction stir dovetailing. Scripta Mater 148: 63-67. DOI: 10.1016/j.scriptamat.2018.01.026.

[11] Reza-E-Rabby M, Ross K, McDonnell M (2020) Numerical simulation and experimental validation of joint performance in aluminum-steel lap welds formed by friction stir dovetailing. $\mathrm{J}$ Mater Process Technol 277: 116459. DOI: 10.1016/j.jmatprotec.2019.116459.

[12] Shen Z, Li WY, Ding Y (2020) Material flow during refill friction stir spot welded dissimilar Al alloys using a grooved tool. J Manuf Process 49: 260-270. DOI: 10.1016/j.jmapro.2019.11.029.

[13] Chen Q, Yang J, Liu X (2019) Effect of the groove type when considering a thermometallurgical-mechanical model of the welding residual stress and deformation in an S355JR-316L dissimilar welded joint. J Manuf Process 45: 290-303. DOI: 10.1016/j.jmapro.2019.07.011.

[14] Watanabe T, Takayama H, Yanagisawa A (2006) Joining of aluminum alloy to steel by friction stir welding. J Mater Process Technol 178(1-3): 342-349. DOI: 10.1016/j.jmatprotec.2006.04.117.

[15] Wan L, Huang Y. Friction stir welding of dissimilar aluminum alloys and steels: A review. Int J Adv Manuf Technol 2018; 99: 1781-1811. DOI: 10.1007/s00170-018-2601-x.

[16] Tanaka T, Morishige T, Hirata T (2009) Comprehensive analysis of joint strength for dissimilar friction stir welds of mild steel to aluminum alloys. Scripta Mater 61(7): 756-759. DOI: 10.1016/j.scriptamat.2009.06.022.

[17] Huang Z, Yanagimoto J (2015) Dissimilar joining of aluminum alloy and stainless steel thin sheets by thermally assisted plastic deformation. J Mater Process Technol 225: 393-404. DOI: 10.1016/j.jmatprotec.2015.06.023.

[18] Li M, Wu RH, Cai S, Chen J (2020) Experimental investigation on friction-stir-assisted incremental forming with synchronous bonding of aluminum alloy and steel sheets. $J$ Mater Eng Perform 29(2): 750-759. DOI: 10.1007/s11665-020-04600-8. 
[19] Govindaraj NV, Lauvdal S, Holmedal B (2013) Tensile bond strength of cold roll bonded aluminium sheets. J Mater Process Technol 213(6): 955-960. DOI: 10.1016/j.jmatprotec.2013.01.007.

[20] Donati L, Tomesani, L (2004) The prediction of seam welds quality in aluminum extrusion. J Mater Process Technol 153-154(22): 366-373. DOI: 10.1016/j.jmatprotec.2004.04.215.

[21] Praveen K, Lingam R, Reddy NV (2020) Tool path design system to enhance accuracy during double sided incremental forming: An analytical model to predict compensations for small/large components. J Manuf Process 58: 510-523. DOI: 10.1016/j.jmapro.2020.08.014

[22] Ai S, Dai R, Long H (2020) Investigating formability enhancement in double side incremental forming by developing a new test method of tension under cyclic bending and compression. J Mater Process Technol 275: 116349. DOI: 10.1016/j.jmatprotec.2019.116349.

[23] Lu B, Fang Y, Xu DK, Chen J (2015) Investigation of material deformation mechanism in double side incremental sheet forming. Int $\mathrm{J}$ Mach Tools Manuf 93: 37-48. DOI: 10.1016/j.jijmachtools.2015.03.007.

[24] Wu RH, Liu XM, Li M, Chen J (2021) Investigations on deformation mechanism of double-sided incremental sheet forming with synchronous thermomechanical steel-aluminum alloy bonding. J Mater Process Technol 294: 117147. DOI: 10.1016/j.jmatprotec.2021.117147.

[25] Moser N, Zhang Z, Ren H, Zhang H, Shi Y, Ndip-Agbor EE, Cao J (2016) Effective forming strategy for double-sided incremental forming considering in-plane curvature and tool direction. CIRP Ann 65: 265-268. DOI: 10.1016/j.cirp.2016.04.131.

[26] Ai S, Lu B, Chen J, Long H, Ou H (2017) Evaluation of deformation stability and fracture mechanism in incremental sheet forming. Int $\mathrm{J}$ Mech Sci 124-125: 174-184. DOI:10.1016/j.jimecsci.2017.03.012.

[27] Commin L, Dumont M, Masse JE (2009) Friction stir welding of AZ31 magnesium alloy rolled sheets: influence of processing parameters. Acta Mater 57(2): 326-334. DOI: 10.1016/j.actamat.2008.09.011.

[28] Cai S, Wu RH, Wang ZH, Meng L, Chen J (2020) Numerical simulation of friction stir-assisted incremental forming with synchronous bonding of heterogeneous sheet metals. Int J Adv Manuf Technol 106: 2747-2763. DOI: 10.1007/s00170-019-04792-x. 


\section{Figures}

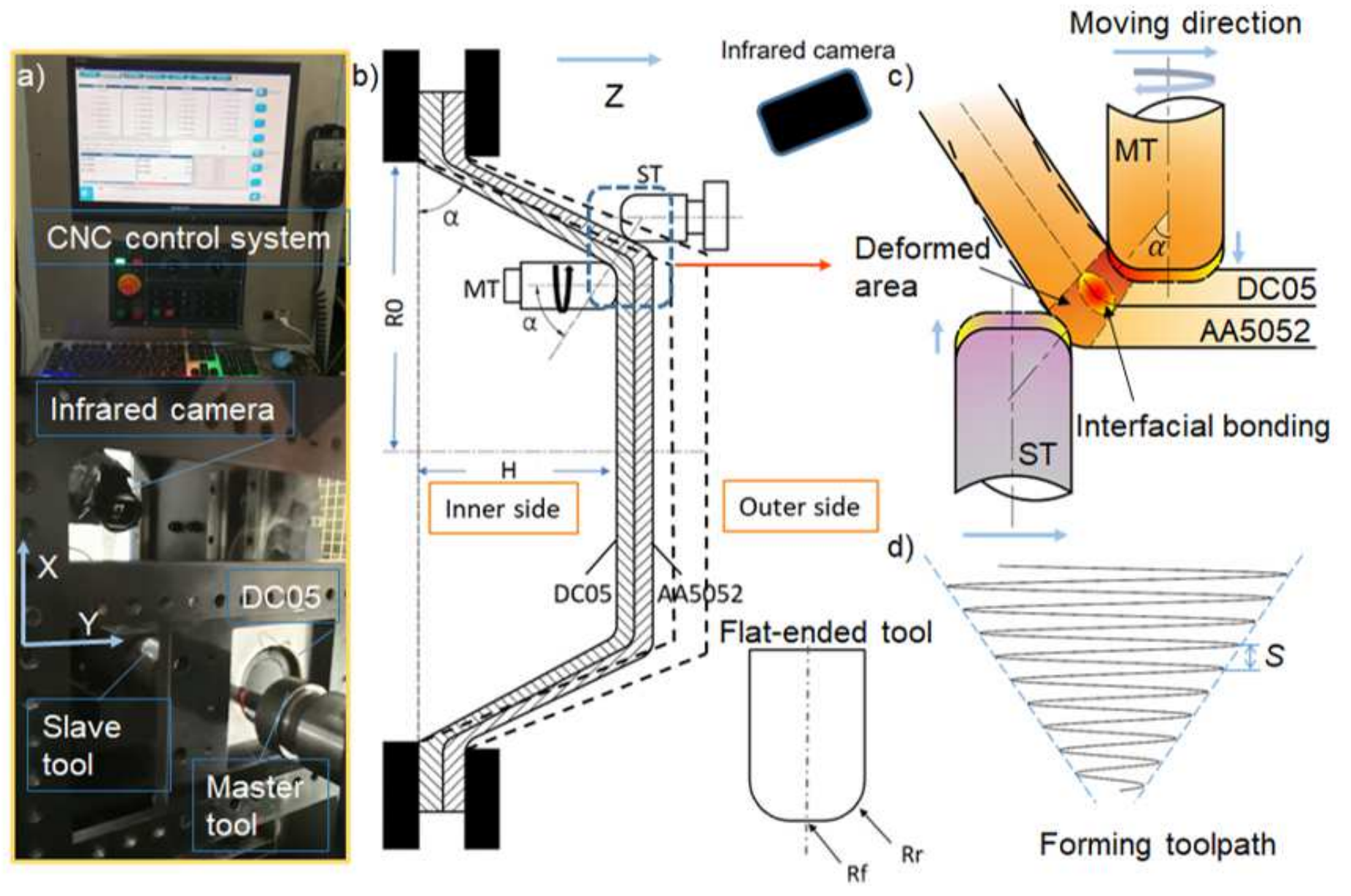

\section{Figure 1}

Forming configuration and schematic illustration of FS-DSIF\&SB process. (a) DSIF forming platform, (b) illustration of FS-DSIF\&SB forming principle, (c) localized loading area, (d) spiral forming tool path with step down S. (A processing video is available in supplemental online material). 


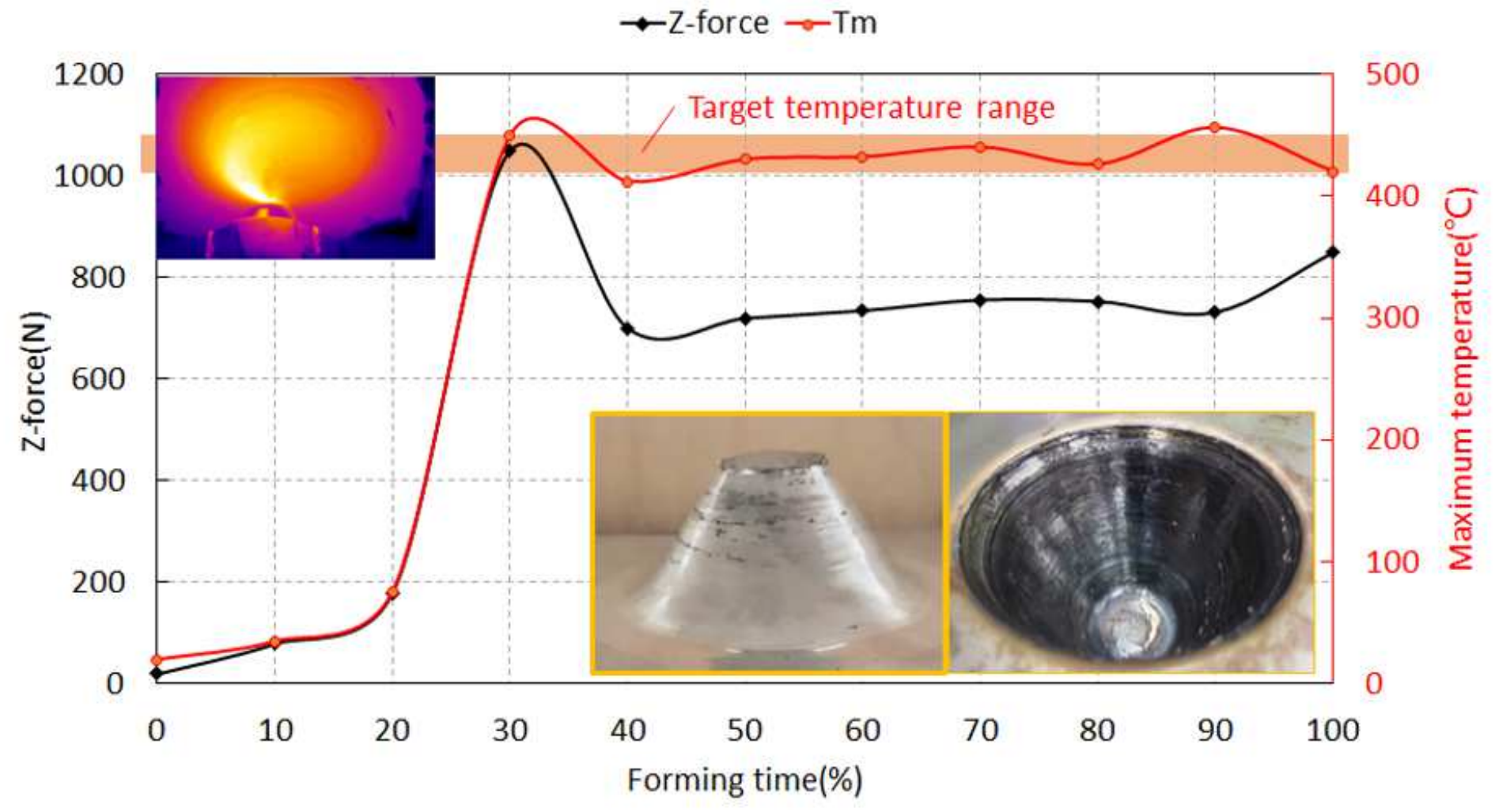

Figure 2

History of MT Z-force and maximum temperature during process.

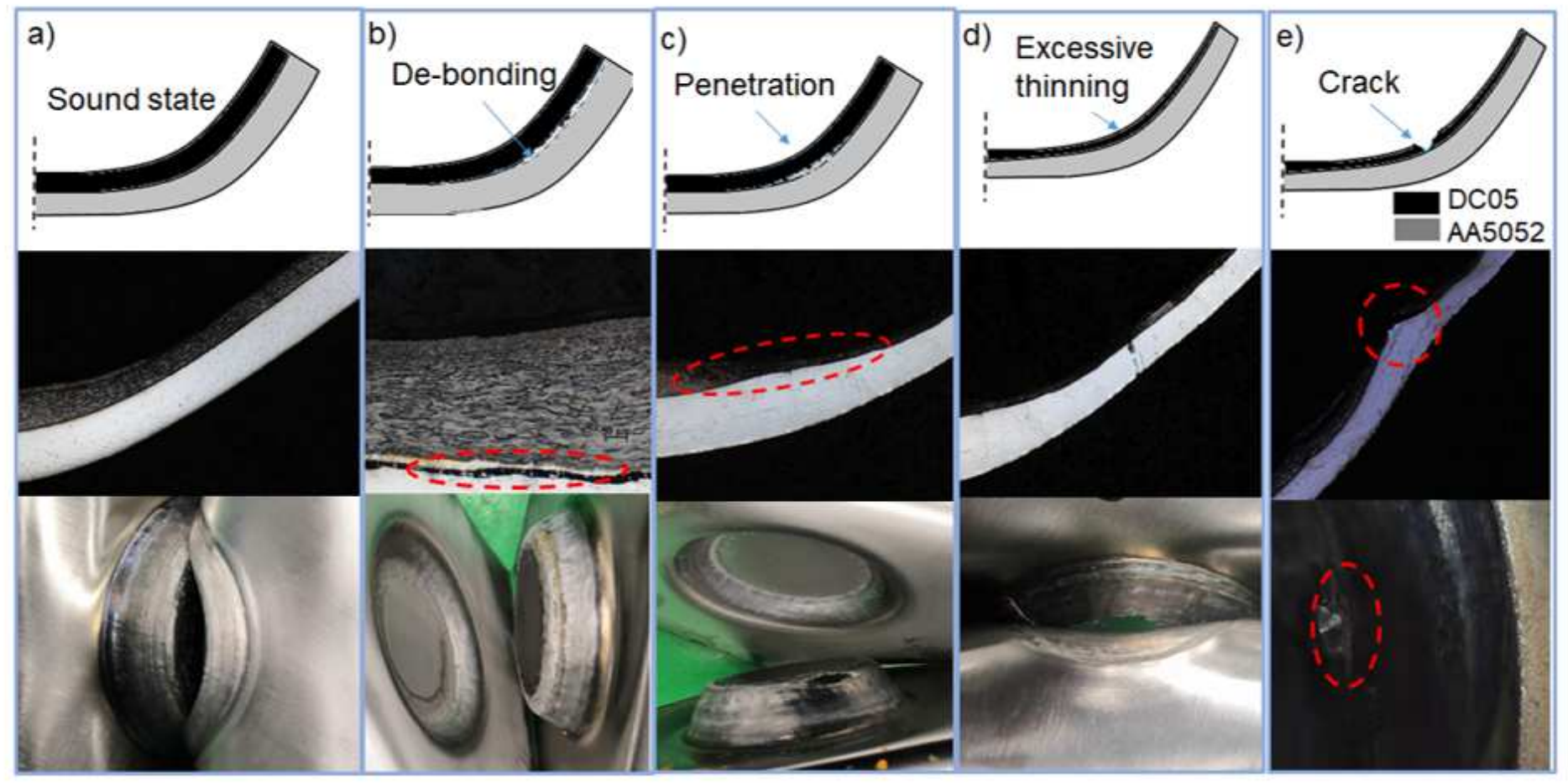

Figure 3 
Illustration and actual process appearance and interfacial peeling behavior of 5 typical types of forming modes.

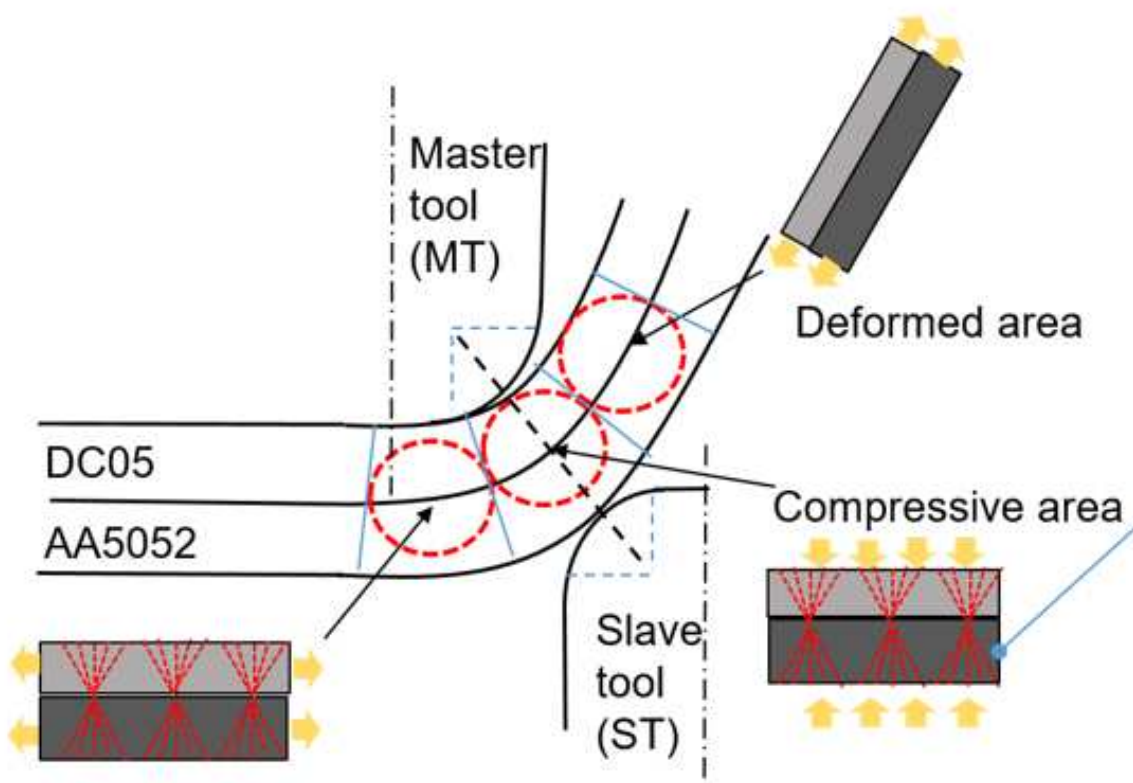

Tensile area

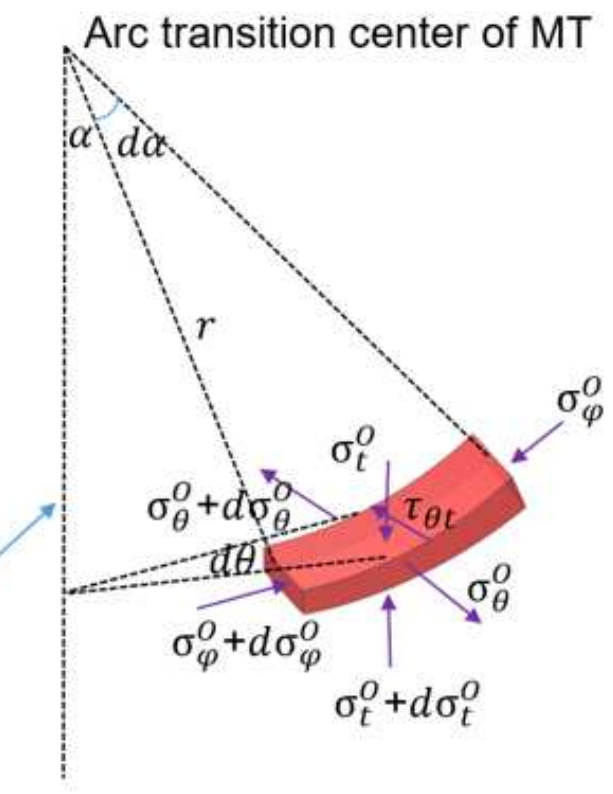

Stress state of element

\section{Figure 4}

Illustration of deformation mode of sheets in FS-DSIF\&SB process.

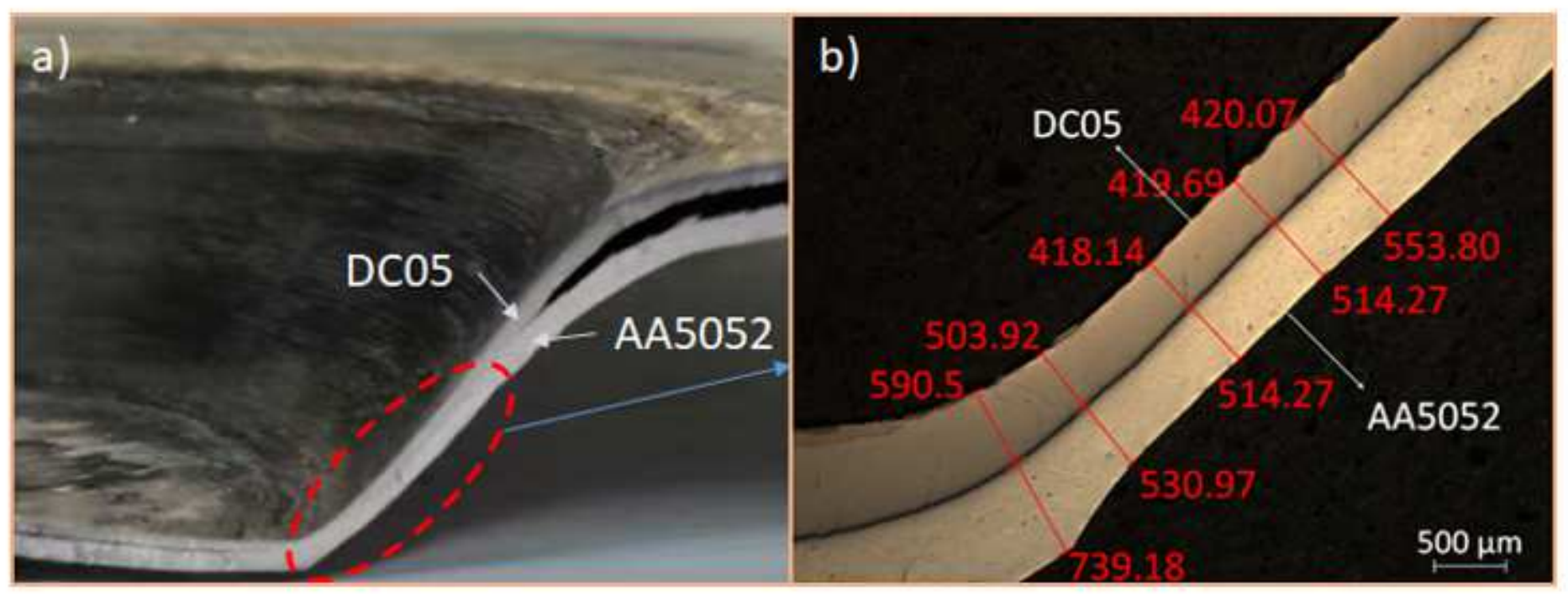

\section{Figure 5}

Fabricated Al/steel laminated part with thickness distribution. (a) successfully fabricated part, (b) wall thickness distribution. 


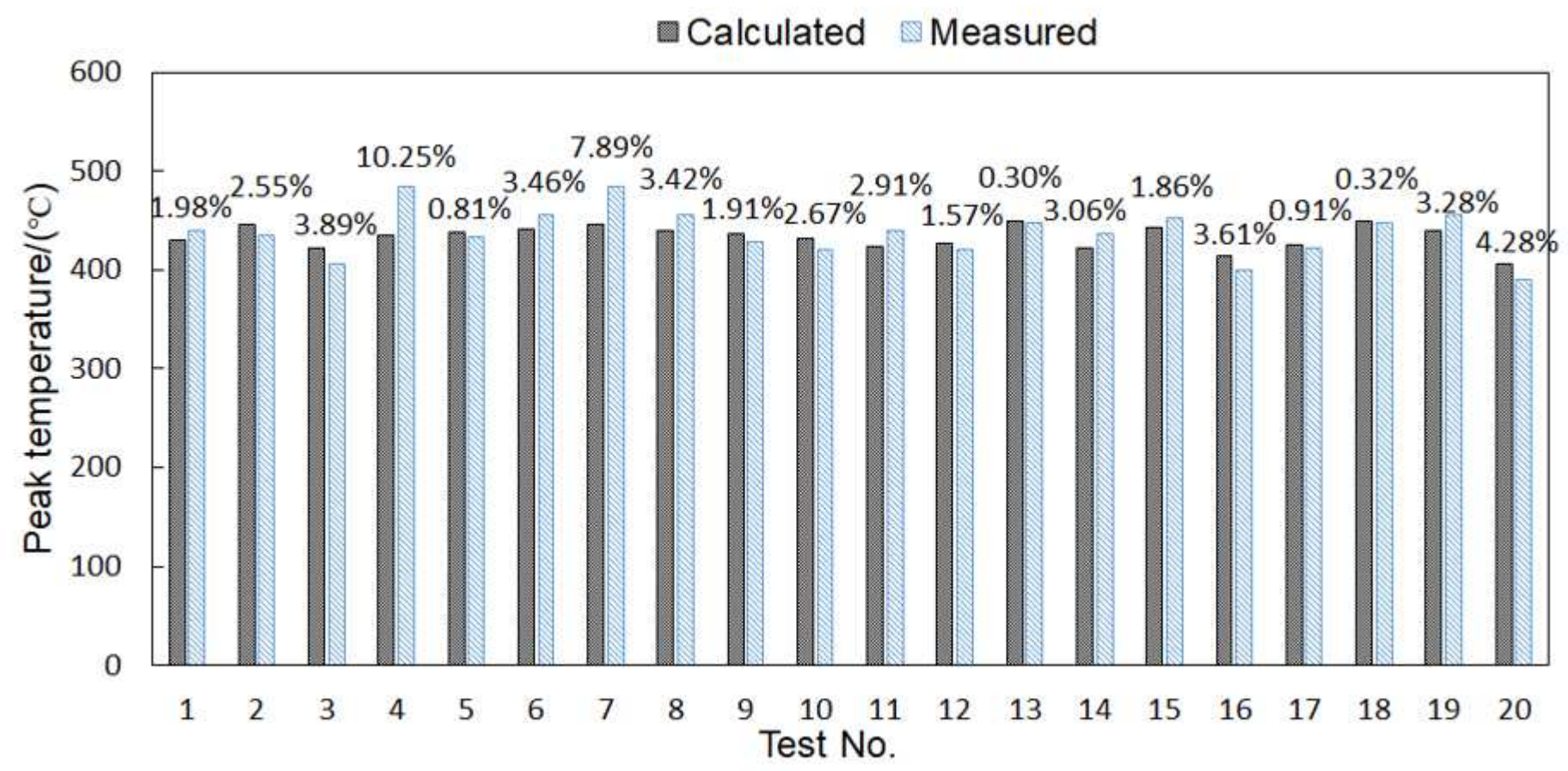

Figure 6

Comparison of calculated and measured peak temperature between prediction and experiment in FSDSIF\&SB tests.

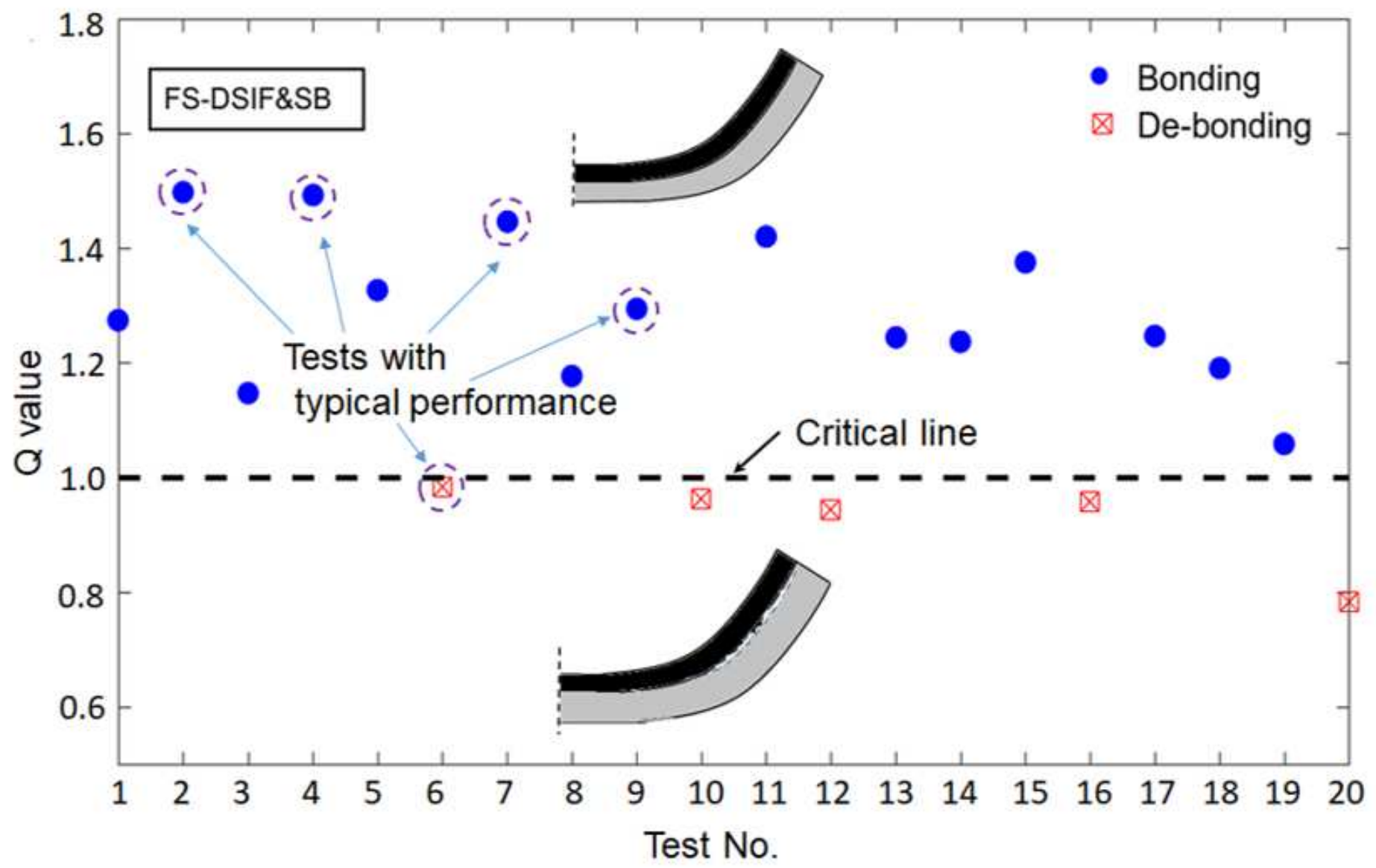




\section{Figure 7}

Prediction model for assessing interfacial bonding states by evaluating $Q$ value.
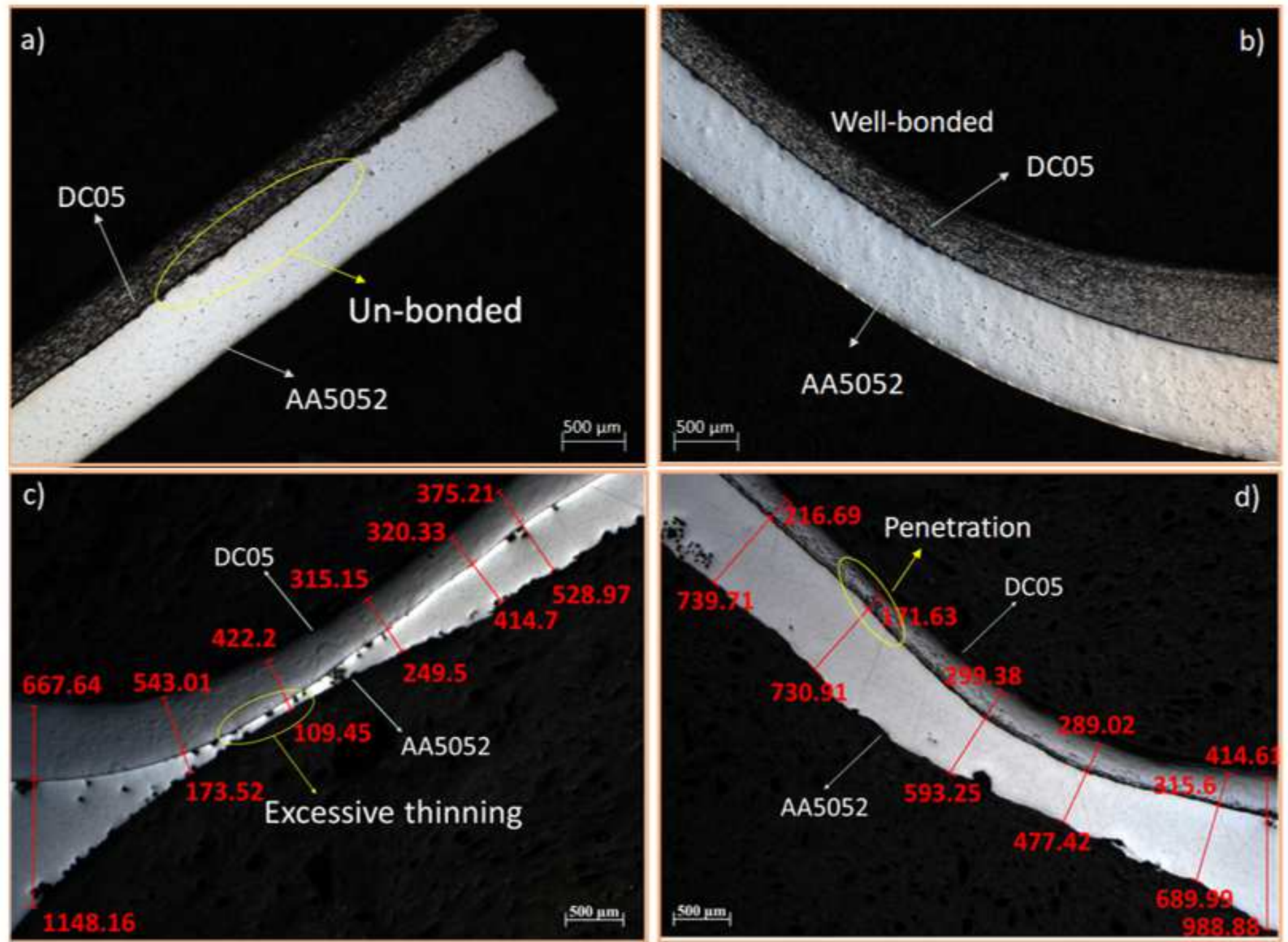

\section{Figure 8}

Performance of fabricated parts with different forming parameters. (a) un-bonded, (b) well-bonded, (c) excessive thinning, (d) penetration. 

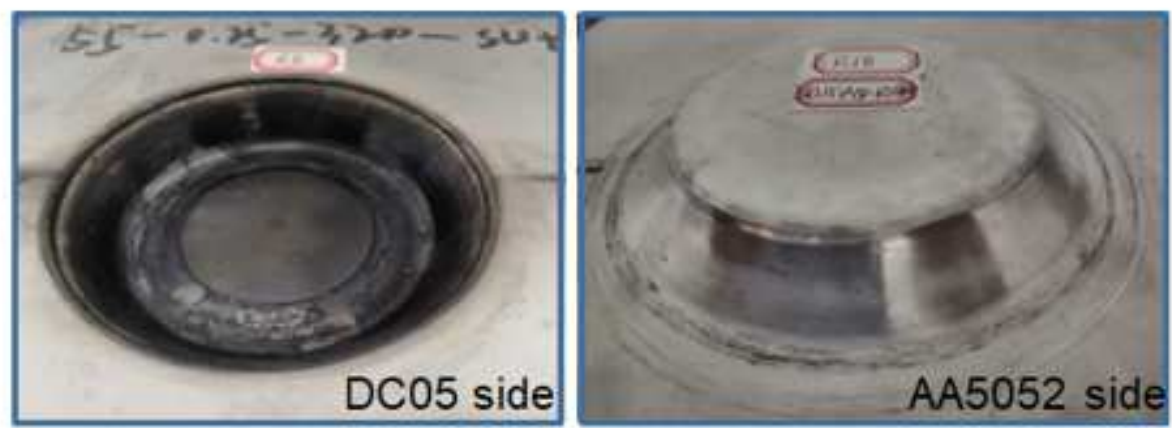

Typical fabricated part with sound bonding

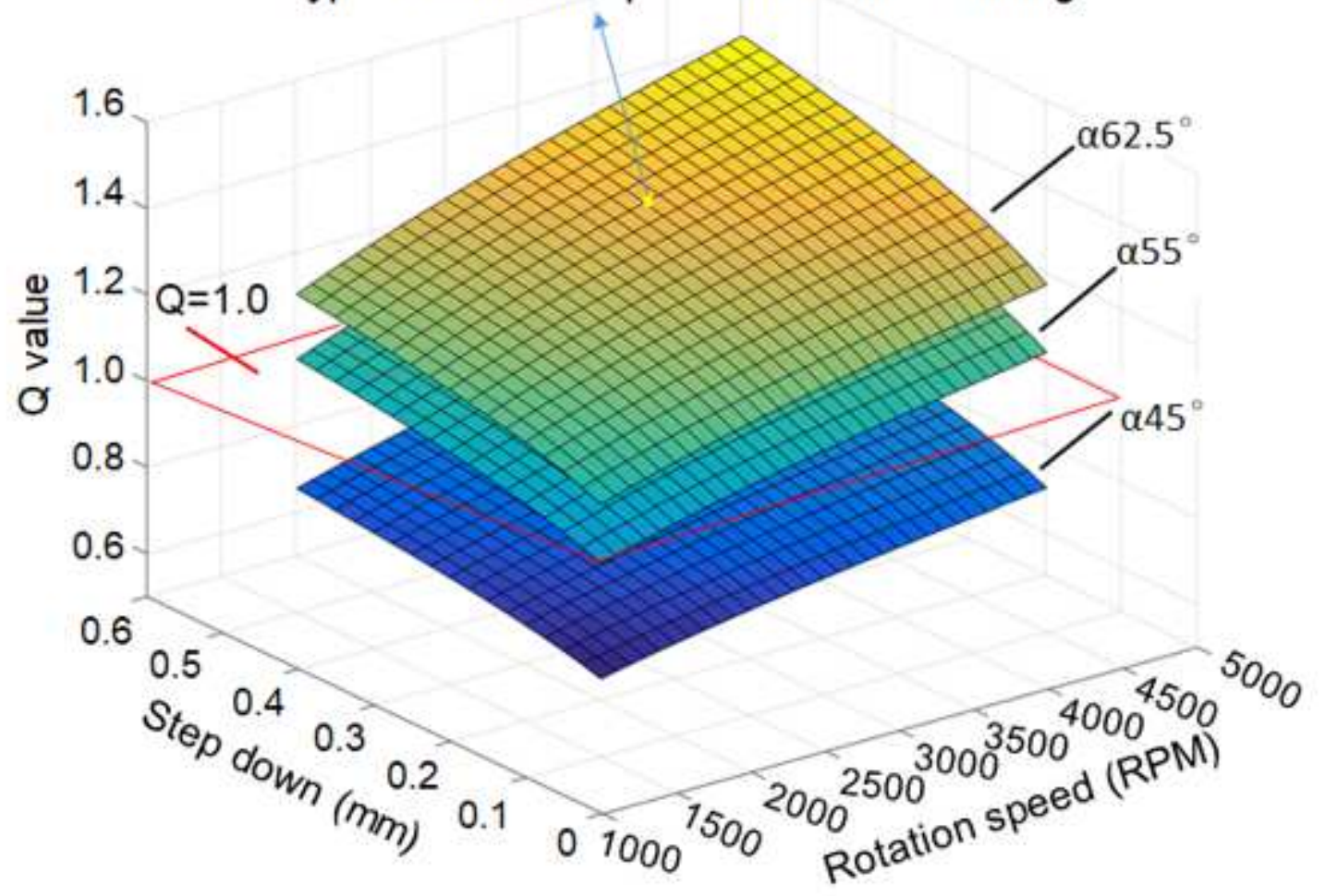

\section{Figure 9}

Process bonding quality predicted by $Q$ response surfaces dependent on forming parameters in FSDSIF\&SB.

\section{Supplementary Files}

This is a list of supplementary files associated with this preprint. Click to download.

- SupplementalprocessingvideoofFSDSIFSB.mp4 